\title{
Treatment of Pulmonary Hypertension
}

\section{Vidya Ramachandraiah ${ }^{1}$, Vishal Sekhri², Wilbert S. Aronow ${ }^{3 *}$ and Dipak Chandy ${ }^{2}$}

${ }^{1}$ Department of Medicine, New York Medical College, Valhalla, NY 10595, USA

${ }^{2}$ Division of Pulmonary, Critical Care and Sleep Medicine, New York Medical College, Valhalla, NY 10595, USA

${ }^{3}$ Divisions of Cardiology and Pulmonary, Critical Care and Sleep Medicine, New York Medical College, Valhalla, NY 10595, USA

\begin{abstract}
Pulmonary Hypertension $(\mathrm{PH})$ is a progressive disease characterised by an increase in the mean pulmonary artery pressure at rest. Based on etiology, $\mathrm{PH}$ is classified into five broad groups. Idiopathic pulmonary arterial hypertension develops secondary to proliferative changes obstructing the pulmonary vasculature leading to structural changes in the heart, finally resulting in right heart failure and premature death. The pathogenesis is not clear but is thought to be due to an imbalance between vasodilating and vasoconstricting chemicals in the pulmonary vasculature. Over the last two decades, a number of effective treatments that help in the management of this disease have been developed by targeting the prostacyclin, endothelin and nitric oxide pathways. Majority of patients receive monotherapy but as the disease affects more than one pathway, there has been interest in using more than one drug in combination to improve symptoms. Combination therapy should probably be used in PAH patients who remain in WHO class III despite being on monotherapy. This review will illustrate the various drugs and combination therapies that are currently being administered or being investigated. In addition, this review will touch upon various surgical interventions that can be considered in patients who show disease progression despite being on aggressive medical therapy.
\end{abstract}

Keywords: Pulmonary hypertension; Vasoreactivity test; Treatment; Combination therapy; Surgical options

Abbreviations: PAH: Pulmonary Arterial Hypertension; PH: Pulmonary Hypertension; PA: Pulmonary Artery; IPAH: Idiopathis Pulmonary Arterial Hypertension; BMPR2: Bone Morphogenic Protein Receptor II; TGF: Trasforming Growth Factor; cGMP: cyclic Guanosine Monophosphate; PDE-5: Phosphodiesterase-5; cAMP: cyclic Adenosine Monophosphate; EKG: Electrocardiogram; CXR: Chest X-Ray; RHC: Right Heart Catheterisation; PFT: Pulmonary Function Tests; ABG: Arterial Blood Gases; HRCT: High Resolution Cat Scan; PCWP: Pulmonary Capillary Wedge Pressure; RF: Rheumatoid Factor; ANA: Antinuclear Antibody; Anti Scl-70: Anti topoisomerase; CT: Cat Scan; TTE: Trans Thoracic Echocardiogram; TEE: Trans Esophageal Cardiogram; RAP: Right Atrial Pressure; FC: Functional Class; RCT: Randomised Control Trial; 6MWD: 6 Minute Walk Distance; PAP: Pulmonary Artery Pressure; CTEPH: Chronic Thromboembolic Pulmonary Hypertension; CCB: Calcium Channel Blockers; PEA: Pulmonary Endarterectomy

\section{Definition}

Pulmonary hypertension is defined as a mean pulmonary artery pressure $\geq 25 \mathrm{~mm} \mathrm{Hg}$ at rest determined by right heart catheterization [1]. Mean PA pressure $>30 \mathrm{~mm} \mathrm{Hg}$ during exercise determined by right heart catheterization is no longer defined as pulmonary hypertension as healthy, especially older, adults can often reach such pressures during exercise $[2,3]$.

\section{Classification}

The current clinical classification of pulmonary hypertension was adapted at the $4^{\text {th }}$ World symposium on PH held at Dana Point, CA in 2008. PH is now divided into five groups based on etiology [4] (Table 1). $\mathrm{PH}$ can also be classified as pre-capillary or post-capillary based on hemodynamic measurements [5] (Table 2). The WHO classifies PAH into four classes based on the degree of symptoms (Table 3).

\section{Pathogenesis}

A multiple hit hypothesis has been postulated for the development of idiopathic pulmonary arterial hypertension. These can be genetic as well as other inciting factors like a coexisting disease or environmental exposure in addition to the underlying predisposition. Possible second

\begin{tabular}{|c|c|}
\hline \multicolumn{2}{|r|}{ Group 1: Pulmonary arterial hypertension } \\
\hline & Idiopathic \\
\hline & $\begin{array}{l}\text { Heritable: associated with specific gene mutations like BMPR2, ALK1, } \\
\text { endoglin, etc }\end{array}$ \\
\hline & Drug- \& toxin-induced \\
\hline & $\begin{array}{l}\text { Associated with: connective tissue diseases, HIV infection, portal hyperten- } \\
\text { sion, congenital heart diseases, schistosomiasis \& chronic hemolytic anemia }\end{array}$ \\
\hline & Persistent pulmonary hypertension of the newborn \\
\hline \multicolumn{2}{|r|}{$\begin{array}{l}\text { Group 1': Pulmonary veno-occlusive disease and/or pulmonary capillary heman- } \\
\text { giomatosis }\end{array}$} \\
\hline \multicolumn{2}{|r|}{ Group 2: PH secondary to left heart disease } \\
\hline & Systolic dysfunction \\
\hline & Diastolic dysfunction \\
\hline & Valvular disease \\
\hline \multicolumn{2}{|r|}{ Group 3: PH secondary to lung diseases and/or hypoxia } \\
\hline & Chronic obstructive pulmonary disease \\
\hline & Interstitial lung disease \\
\hline & Other diseases with a mixed restrictive \& obstructive pattern \\
\hline & Sleep disordered breathing \\
\hline & Alveolar hypoventilation disorders \\
\hline & Chronic exposure to high altitude \\
\hline & Developmental abnormalities \\
\hline \multicolumn{2}{|r|}{ Group 4: Chronic thromboembolic pulmonary hypertension } \\
\hline \multicolumn{2}{|r|}{ Group 5: PH due to multi-factorial/unclear mechanisms. } \\
\hline & Hematologic: myeloproliferative disorders, splenectomy \\
\hline & Systemic: sarcoidosis, pulmonary Langerhans cell histiocytosis \\
\hline & $\begin{array}{l}\text { Metabolic disorders: glycogen storage disorders, Gaucher disease, thyroid } \\
\text { disorders }\end{array}$ \\
\hline & $\begin{array}{l}\text { Others: tumoral obstruction, fibrosing mediastinitis, chronic renal failure on } \\
\text { dialysis }\end{array}$ \\
\hline
\end{tabular}

Table 1: Updated clinical classification of pulmonary hypertension [4] (Dana Point, 2008).

*Corresponding author: Wilbert S. Aronow MD, FCCP, FACC, FAHA, Cardiology Division, New York Medical College, Macy Pavilion, Room 138, Valhalla, NY 10595, USA, Tel: 914-493-5311; Fax: 914-235-6274; E-mail: wsaronow@aol.com

Received March 02, 2012; Accepted April 13, 2012; Published April 15, 2012

Citation: Ramachandraiah V, Sekhri V, Aronow WS, Chandy D (2012) Treatment of Pulmonary Hypertension. J Pulmon Resp Med S4:001. doi:10.4172/2161-105X. S4-001

Copyright: (c) 2012 Ramachandraiah V, et al. This is an open-access article distributed under the terms of the Creative Commons Attribution License, which permits unrestricted use, distribution, and reproduction in any medium, provided the original author and source are credited. 
Citation: Ramachandraiah V, Sekhri V, Aronow WS, Chandy D (2012) Treatment of Pulmonary Hypertension. J Pulmon Resp Med S4:001. doi:10.4172/2161-105X.S4-001

\begin{tabular}{|l|}
\hline Pre-capillary: Mean PA pressure $\geq 25 \mathrm{~mm} \mathrm{Hg}$ with PCWP $\leq 15 \mathrm{~mm} \mathrm{Hg}$. \\
\hline This includes \\
\hline - $\quad$ Group 1: Pulmonary arterial hypertension \\
\hline - $\quad$ Group 3: Secondary to diseases of lungs and/or hypoxia \\
\hline - $\quad$ Group 4: Chronic thromboembolic $\mathrm{PH}$ \\
\hline - $\quad$ Group 5: Pulmonary hypertension due to multifactorial/unclear etiology. \\
\hline Post-capillary: Mean PA pressure $\geq 25 \mathrm{~mm} \mathrm{Hg}$ with PCWP $>15 \mathrm{~mm} \mathrm{Hg}$. \\
\hline This includes \\
\hline - Group 2: Secondary to left heart disease \\
\hline
\end{tabular}

Table 2: Classification of $\mathrm{PH}$ based on the pulmonary capillary wedge pressure [5]

Class I: No limitation of ordinary physical activity.

Class II: Mild limitation of ordinary physical activity. No discomfort at rest.

Class III: Marked limitation of physical activity even with less than ordinary activity. No discomfort at rest.

Class IV: Unable to perform any physical activity and symptomatic even at rest.

Limitations to physical activity in each class may be due to increased dyspnea, chest pain, fatigue or syncope

Table 3: WHO functional classification of PAH.

hits include congenital left-to-right shunts, human herpes virus-8, human immunodeficiency virus, drugs like anorexigens, etc. These processes are eventually thought to work by increasing endothelin levels or decreasing nitric oxide and prostacyclin levels [6].

\section{Genetic mechanisms}

\section{Bone morphogenetic protein receptor type II:}

Bone morphogenetic protein receptor type II is a component of the heteromeric vascular smooth muscle cell BMPR receptor and a member of the transforming growth factor beta superfamily. A mutation in the BMPR2 results in an alteration of apoptosis that favors endothelial cellular growth and proliferation in response to certain injuries.

\section{Activin-like kinase type-1 receptor:}

This is also a member of the TGF- $\beta$ family. This mutation is present in some patients with hereditary hemorrhagic telangiectasia and $\mathrm{PAH}$.

\section{Serotonin transporter genes:}

A mutation of the serotonin gene promoter results in pulmonary artery smooth muscle hypertrophy and is present in homozygous form in $65 \%$ of patients with idiopathic PAH.

\section{Molecular Mechanisms}

The development of $\mathrm{PH}$ is thought to be due to an imbalance in vascular homeostasis with increase in factors promoting chronic vasoconstriction, endothelial dysfunction, smooth muscle hypertrophy and proliferation.

Understanding pathogenesis of IPAH is important as the mechanism of action of medications that have been currently approved for the management of IPAH is by interfering with these pathways. However, it is not known if these mechanisms are applicable to the other types of $\mathrm{PH}$.

Endothelin pathway: Increased endothelin-1 production interacts with the endothelin receptors on the vascular smooth muscle cells to promote smooth muscle proliferation and vasoconstriction. Endothelin receptor antagonists thus promote vasodilatation and inhibit smooth muscle proliferation.

Nitric oxide pathway: Nitric oxide promotes vasodilatation, inhibits proliferation of smooth muscle and fibroblasts and platelet aggregation via the cyclic guanosine monophosphate mediated pathway. However cGMP is rapidly degraded by phosphodiesterase- 5 isoenzymes. PDE5 inhibitors thus enhance cGMP levels and promote vasodilatation.

Prostacyclin pathway: Pulmonary endothelial cell dysfunction with down regulation of prostacyclin synthase causes low endogenous prostacyclin that promotes vasoconstriction, thrombotic arteriopathy and progressive intimal proliferation and fibrosis. Prostacyclin analogues promotes cyclic adenosine monophosphate mediated vasodilatation, inhibit platelet aggregation and smooth muscle and fibroblast proliferation.

\section{Diagnosis of Pulmonary Hypertension}

Patients suspected of $\mathrm{PH}$ need to undergo rigorous testing first to confirm that $\mathrm{PH}$ is indeed present and then to identify the underlying

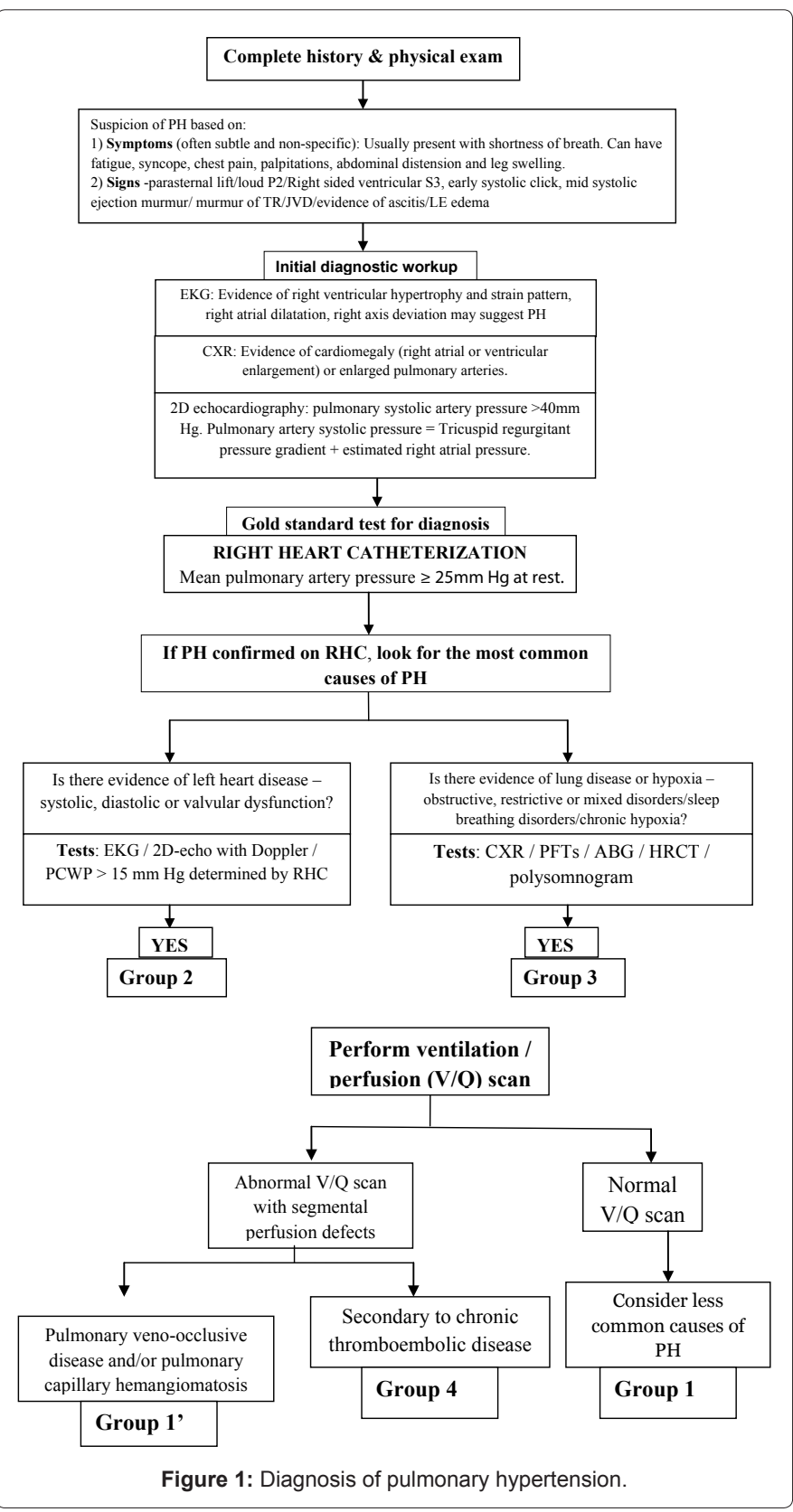




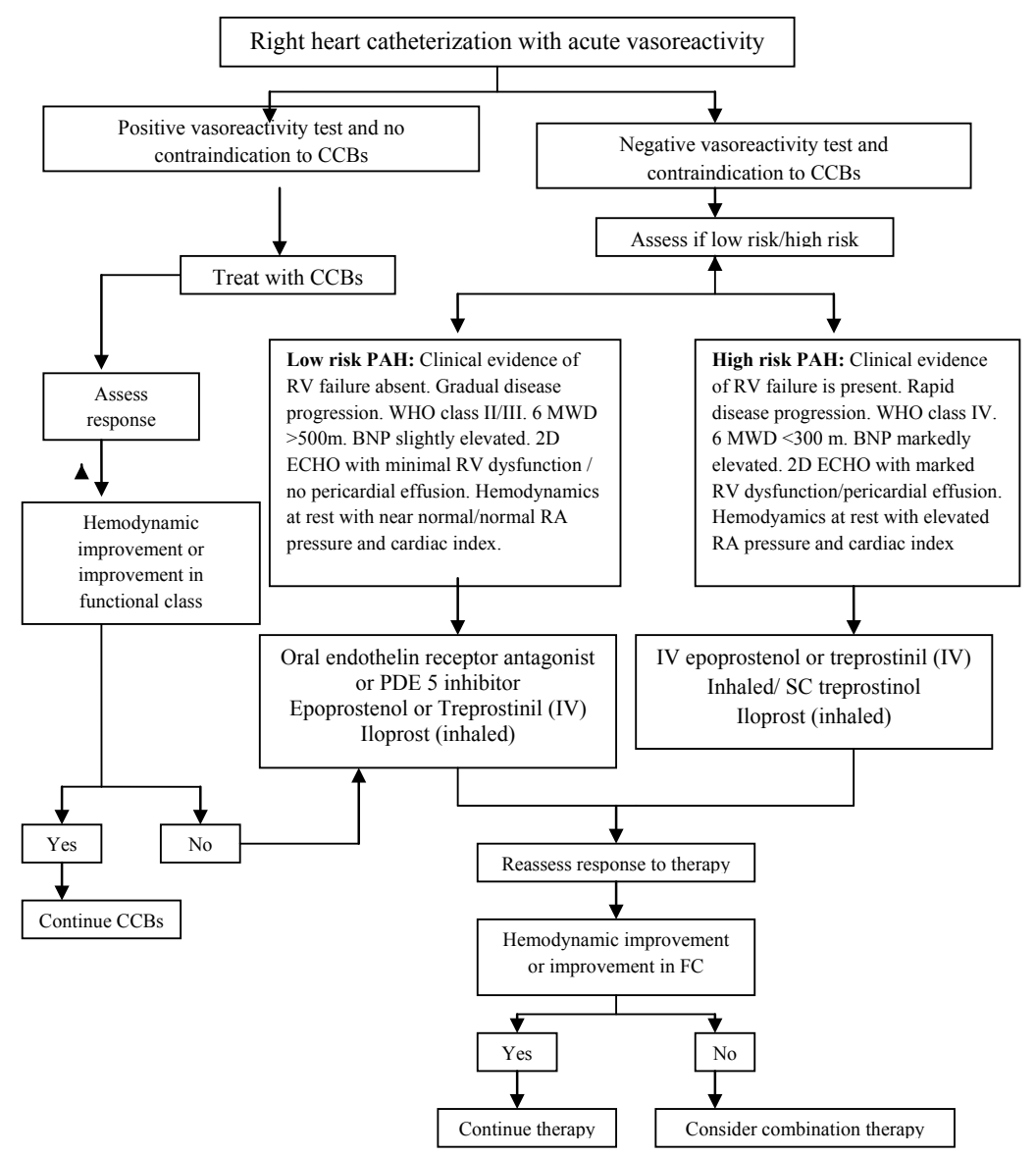

Figure 2: Vasoreactivity testing.

cause. The sequence of these tests is dependent on the initial history and examination, and a generalised guide to follow have been detailed in Figure 1.

\section{Management of Pulmonary Arterial Hypertension}

\section{General measures}

Patients should be encouraged to exercise but should be advised to avoid activities that cause significant dyspnea, dizziness or chest pain. Also, supervised exercise rehabilitation is recommended in the physically deconditioned as there is evidence that it improves exercise capacity [7]. PAH is an absolute contraindication to pregnancy as it carries a mortality rate of $30-50 \%$. Therefore, patients should be advised against becoming pregnant [8-10]. Patients who decide to continue with their pregnancy despite knowing the risks involved should be treated for PAH and very closely followed throughout their pregnancy. Influenza and pneumococcal vaccines are recommended in all patients with $\mathrm{PAH}$ as these infections carry significant mortality risk [11]. Epidural anesthesia is preferable to general anesthesia for elective surgeries in patients with PAH.

\section{Supportive Therapies}

Coumadin: Anticoagulation with coumadin is indicated in all patients with IPAH, heritable PAH and PAH secondary to anorexigens if there are no contraindications. These are the groups where there is evidence that favors use of anticoagulation. Post-mortem studies have shown that patients with IPAH have a higher prevelance of vascular thrombotic lesions [12].

Diuretics: To provide symptomatic relief in patients that are fluid overloaded due to heart failure.

Oxygen: Supplemental oxygen to maintain $\mathrm{O}_{2}$ saturation $>90 \%$ is indicated in patients with parenchymal lung disease or advanced pulmonary vascular disease with partial pressure of oxygen in arterial blood is persistently lower than $60 \mathrm{mmHg}$. Supplemental $\mathrm{O}_{2}$ improves hypoxia and hypoxic pulmonary vasoconstriction.

Digoxin: Has inotropic activity, increases resting cardiac output and could be used to lower ventricular rates in patients with PAH who develop atrial tachyarrythmias that are not well tolerated in the setting of heart failure [13].

\section{Specific Drug Therapies}

Vasodilator testing with short acting agents like inhaled nitric oxide or intravenous epoprostenol or adenosine should be performed in all patients with IPAH during the initial RHC as they may then be potential candidates for treatment with calcium channel blockers. This should not be performed in patients who have right heart failure or who are hemodynamically unstable as they are unlikely to tolerate calcium channel blockers.

Pulmonary vasoreactivity is defined as a decrease in the mean PA pressure of at least $10 \mathrm{~mm} \mathrm{Hg}$ to a mean PA pressure $<40 \mathrm{~mm} \mathrm{Hg}$ with an increase or no change in cardiac output. Only about $10 \%$ o patients 
have a positive vasoreactivity test [14]. The patients who have positive vasoreactivity testing are then treated according to schema as outlined in Figure 2.

\section{Positive Acute Vasoreactivity Testing}

\section{Calcium channel blockers}

Calcium channel blockers act by inhibiting calcium influx into the smooth muscle cells, thereby inhibiting vascular smooth muscle contraction. They also decrease cardiac contractility, AV conduction and heart rate. CCBs are indicated only in patients who have had a positive acute vasoreactivity test $[15,16]$ and have no contraindications to CCBs like heart failure. Only $10 \%$ of patients with IPAH are longterm responders to CCBs. Drugs of choice are nifedipine, diltiazem and amlodipine. Choice of CCB is based on the patient's heart rate. Nifedipine and amlodipine are preferred in patients with relative bradycardia as they tend to cause peripheral vasodilatation and reflex tachycardia whereas diltiazem is preferred in patients with relative tachycardia where diltiazem acts directly on the AV node to decrease conduction through the node, thereby decreasing the heart rate. Verapamil is usually avoided due to its negative ionotropic activity.

Dosage of CCBs: Maximum daily doses of drugs that have been shown to be effective in IPAH are:

Nifedipine: 120-240mg/day

Diltiazem: 240-960mg/day

Amlodipine: 20-30mg/day

It is recommended to start at lower doses and gradually increase the dose based on patient response and ability to tolerate higher doses. Higher doses are usually required to achieve maximal benefit.

A side effect of dihydropyridine CCBs (nifedipine and amlodipine) is peripheral edema. A centrally acting CCB like diltiazem can cause systemic hypotension due to its negative ionotropic effect on the heart.

Another major limitation to the use of CCBs in PAH is that an initial CCB responder may become a non-responder or show diminished benefit as the disease progresses.

Patients who are started on CCBs should be followed closely to assess response to therapy and side-effects. They should be constantly assessed for an improvement in functional classification (WHO) and with a RHC after 3-4 months of starting therapy to look for hemodynamic improvement. Patients who do not show adequate response to CCBs should be switched to a different treatment modality.

\section{Negative Acute Vasoreactivity Testing}

Treatment of patients with a negative vasoreactivity test or who were not candidates for an acute vasoreactivity test due to right heart failure or hemodynamic instability is based on their risk factors and severity of their PAH.

Three major classes of drugs have approved for the treatment of $\mathrm{PAH}$ who have a negative acute vasoreactive test or who are nonresponders to $\mathrm{CCBs}$ or who have contraindications to CCBs (Table 4).

\section{Prostacyclin Analogues}

They promote cAMP mediated vasodilation, inhibit platelet aggregation and smooth muscle and fibroblast proliferation.

\section{Epoprostenol}

Intravenous epoprostenol was FDA approved for the treatment of $\mathrm{PAH}$ in 1995 and has remained the first line therapy for treatment of WHO class IV patients and is also often used as rescue therapy.

Long term use of continuous iv epoprostenol improves exercise capacity, hemodynamics [17], delays lung transplantation in severely ill patients and is the only medication that has been proven to improve survival [18].

In addition to IPAH, iv epoprostenol has been used in PAH associated with HIV [19], scleroderma [20], portopulmonary hypertension [21] and congenital heart disease.

Epoprostenol is rapidly hydrolyzed in the blood into its metabolites and has a very short half-life of 3-5 minutes. It is also known to be an irritant to peripheral veins. Long term use of epoprostenol requires a central venous catheter and portable infusion pumps. Dose of epoprostenol infusion is gradually increased over several weeks, starting at a dose of $1-2 \mathrm{ng} / \mathrm{kg} / \mathrm{min}$ and titrated up by $1-2 \mathrm{ng} / \mathrm{kg} / \mathrm{min}$ every 1-2 days initially and less frequently thereafter until desired effect (improved exercise tolerance and hemodynamic parameters) or dose limiting pharmacologic effects occur.

Eporostenol is contraindicated in patients who have CHF due to severe left ventricular systolic dysfunction and in those who develop pulmonary edema during dose initiation.

Side effects of iv epoprostenol are due to systemic vasodilatory effect and most patients experience hypotension, flushing, jaw pain, headache, diarrhea, nausea or vomiting. There is also an increased bleeding risk due to inhibition of platelet aggregation. Side-effects are dose related and are usually well tolerated. Complications involve rebound pulmonary hypertension and acute right ventricular failure if infusion is abruptly discontinued (including interruptions in the drug delivery system). Therefore, if dose limiting adverse effects occur, the infusion rate has to be decreased gradually.

Catheter related infections are also a concern as these patients require an indwelling central venous catheter for continuous iv infusion for prolonged periods of time [22].

\section{Treprostinil}

Treprostinil is a prostacyclin analogue that is similar to epoprostenol in its mechanism of action but has a longer half life of approximately 4 hours and hence can be administered subcutaneously, intravenously or by inhalation.

Subcutaneous and intravenous treprostinil: Subcutaneous treprostinil was FDA approved in 2002 followed by FDA approval of iv treprostinil in 2005 for treatment of patients with PAH WHO class II-IV. They are also used to treat patients with PAH requiring to be transitioned from epoprostenol.

Patients are started at an initial dose of $1.25 \mathrm{ng} / \mathrm{kg} / \mathrm{min} \mathrm{sc} / \mathrm{iv}$ (reduced to $0.625 \mathrm{ng} / \mathrm{kg} / \mathrm{min}$ if initial dose not tolerated) and increased by $1.25 \mathrm{ng} / \mathrm{kg} / \mathrm{min}$ every week for 4 weeks followed by $2.5 \mathrm{ng} / \mathrm{kg} /$

\begin{tabular}{|l|l|}
\hline Prostacyclin analogues & $\begin{array}{l}\text { Epoprostenol (iv) Treprostinil (sc/iv/in- } \\
\text { haled) Iloprost (inhaled) }\end{array}$ \\
\hline Endothelin receptor antagonists & Bosentan (po) Ambrisentan (po) \\
\hline Phosphodiesterase type 5 inhibitors & $\begin{array}{l}\text { Sildenafil (po) Tadalafil (po) Nitric oxide } \\
\text { (inhaled) }\end{array}$ \\
\hline
\end{tabular}

Table 4: Drugs for treatment of PAH when vasoreactivity test is negative. 
min every week to establish a dose at which there is symptomatic improvement up to a maximum of $40 \mathrm{ng} / \mathrm{kg} / \mathrm{min}$.

The sc route is preferred to the iv route as the latter requires a long term central venous catheter and is associated with risks of blood stream infections and sepsis. IV infusion is reserved for patients who are intolerant to the sc route.

For transitioning patients from epoprostenol, treprostinil has to be started at $10 \%$ of epoprostenol dose and titrated up slowly while reducing the dose of epoprostenol.

Inhaled treprostinil: Inhaled treprostinil was approved by the FDA in 2009 for patients with PAH WHO class III and has been shown to improve 6 minute walk distance [23].

Patients are started at an initial dose of $18 \mathrm{mcg}$ ( 3 breaths) via nebulization 4 times a day and increased by $18 \mathrm{mcg}$ ( 3 breaths)/dose every 1-2 weeks to a maximum of $54 \mathrm{mcg}$ ( 9 breaths) 4 times a day.

The longer half life of treprostinil as compared to epoprostenol reduces the risk of rebound $\mathrm{PAH}$ or cardiovascular collapse in case of abrupt discontinuation of drug although the risk still exists. Infusion site pain and local reaction are the most common side-effects of SC treprostinil seen in $80-85 \%$ of the patients [24]. Risk of hypotension due to systemic vasodilation, headache, nausea, vomiting, diarrhea and increased bleeding risk due to inhibition of platelet aggregation are similar to epoprostenol.

Iloprost: Iloprost was the first inhaled prostacyclin analogue that was FDA approved in 2004 for the treatment of patients with PAH who are WHO class III or IV and patients with inoperable chronic thromboembolic pulmonary hypertension [25]. It has shown efficacy and improved performance on 6 minute walk test both as monotherapy and combination therapy with bosentan [26]

Iloprost is started at a dose of $2.5 \mathrm{mcg}$ nebulization 6-9 times a day and titrated up to a dose of 5 mcg 6-9 times a day if well tolerated and maintained at that dose, the maximum daily dose being $45 \mathrm{mcg}$.

Flushing, cough and headache are the most common side effects reported with iloprost though it can also cause bronchospasm, especially in patients with hyperreactive airways. Systolic blood pressure $<85 \mathrm{~mm} \mathrm{Hg}$ is a contraindication to iloprost as it can worsen systemic hypotension due to its vasodilatory effect.

\section{Endothelin Receptor Antagonists}

Endothelin receptor antagonists bind to the endothelin receptors on vascular smooth muscles to promote vasodilatation and inhibit smooth muscle proliferation.

\section{Bosentan}

Bosentan is a competitive antagonist of endothelin receptors that was FDA approved in 2001 for patients with PAH class III or IV and has been shown to improve 6 minute walk distance $[27,28]$.

Dosage of bosentan for the treatment of PAH is based on the weight of the patient. In patients weighing $<40 \mathrm{~kg}$, bosentan is started and maintained at $62.5 \mathrm{mg}$ PO BID and in those weighing $>40 \mathrm{~kg}$, it is started at $62.5 \mathrm{mg}$ PO BID for 4 weeks and then increased to a maintenance dose of $125 \mathrm{mg}$ PO BID. During discontinuation of treatment, dose reduction to $62.5 \mathrm{mg}$ PO BID for 3-7 days is preferable.

Bosentan has a half life of 5-8 hrs and is metabolized in the liver and primarily excreted in bile.
Major toxicity associated with bosentan is hepatotoxicity by induction of Cytochrome P450 enzyme in the liver and hence require baseline and monthly monitoring of liver function tests. It is better to avoid bosentan if the baseline AST/ALT is $>3$ times the upper limit of normal as monitoring liver injury may be more difficult. Bosentan has to be discontinued if AST/ALT elevation occurs along with increase in bilirubin $\geq 2$ times the upper limit of normal or clinical signs of liver injury occur. Dose related decrease in hemoglobin may occur and it is necessary to monitor hemoglobin at baseline and then at 1 and 3 months and every 3 months thereafter. Headache, nasopharyngitis and fluid retention are other common side-effects. Bosentan also reduces the levels of sildenafil by $50 \%$ when used together; hence the dose of sildenafil needs to be increased accordingly. Also by induction of Cytochrome P450 enzyme, warfarin metabolism is upregulated and will therefore need increase in the dose of warfarin.

Bosentan is contraindicated in pregnancy due to the risk of teratogenesis. Hence in any female patient of child bearing age with $\mathrm{PAH}$, pregnancy has to e excluded before starting therapy. Female patients should be strictly advised to avoid pregnancy (at least 2 reliable methods of contraception are recommended) during therapy and for 4 weeks after the therapy is discontinued.

\section{Ambrisentan}

Ambrisentan is a selective endothelin receptor antagonist which predominantly binds to endothelin receptor A, that was FDA approved in 2007 for treatment of PAH WHO-FC II and III that has been proven to improve 6 minute walk distance [29]. It is used at a dose of $5 \mathrm{mg} P O$ once daily, and can be increased to $10 \mathrm{mg}$ PO once daily if the lower dose is well tolerated.

The most common side effects of ambrisentan are fluid retention, peripheral edema and headache. The risk of liver function abnormalities is significantly lower when compared with bosentan. No significant interaction of ambrisentan with sildenafil or warfarin has been known to occur.

Risk of teratogenicity is similar to bosentan and pregnancy has to be ruled out before starting therapy and strict contraception has to be advised during therapy and for 4 weeks after discontinuation of therapy.

\section{Phosphodiesterase Inhibitors}

Nitric oxide promotes vasodilatation, inhibits smooth muscle and fibroblast proliferation and platelet aggregation via the cGMP mediated pathway. However cGMP is rapidly degraded by PDE 5 isoenzymes. PDE 5 inhibitors thus enhance cGMP levels and promote vasodilation.

\section{Sildenafil}

Sildenafil is a PDE 5 inhibitor that was FDA approved in 2005 for the treatment of WHO class II or III and has been shown to significantly improve the 6 minute walk test, functional capacity and mean PA pressure [30].

The dose approved for treatment of PAH is $20 \mathrm{mg}$ orally three times a day (max 60mg/day)

Sildenafil has a half life of approximately $4 \mathrm{hrs}$ and is metabolized by hepatic P450 enzyme and excreted predominantly in feces. Significant interactions with drugs that are metabolized by $\mathrm{P} 450$ have been known to occur. Most common side effects of sildenafil are headache, epistaxis, insomnia, flushing and dyspepsia. Concomitant use of any nitrate within 24-48 hours can cause significant hypotension. 


\section{Tadalafil}

Tadalafil is a PDE 5 inhibitor that was FDA approved in 2009 for the treatment of WHO class II or III at a dose of $40 \mathrm{mg}$ orally once daily. It has been shown to improve 6 minute walk distance [31]

Tadalafil has a longer half life and is metabolized via hepatic P450 enzyme. The most common side effects of tadalafil are headache, back pain and dyspepsia. Like sildenafil, concomitant use of nitrates with tadalafil within 24-48 hrs can cause potentially fatal hypotension and hence is contraindicated.

\section{Combination Therapy}

All the therapies outlined above have improved patient symptoms, exercise capacity and quality of life although there is no cure of the disease itself. The effects can be characterised as modest at best and the majority of PAH patients will eventually deteriorate clinically. Many clinical studies have been done trying to find if various classes of drugs when combined lead to better endpoints. There is a lot of variability as to which combinations are effective, when these combination therapies should be initiated and whether these agents should be discontinued if they are not clearly beneficial.

\section{Prostanoids and endothelin receptor antagonists}

BREATHE-2: This study was the first RCT using combination therapy in PAH [32]. In this study participants with NYHA class III or IV were started on epoprostenol and after 48 hours they were randomly assigned to two groups. One group received bosentan while the other group received a placebo. The patients were followed for 16 weeks and the results showed that there was greater reduction in pulmonary vascular resistance in the combination arm.

STEP-1: This study randomised 67 patients in two groups. All patients received bosentan for four weeks and they were then randomised to receive either iloprost inhalations or placebo in addition [26]. This led to improvement in the 6-MWD as well as in the functional class. They also demonstrated that time to clinical worsening improved and that the combination was well tolerated. This trial led the FDA to approve the combination treatment in 2005 [33].

\section{Prostanoids and PDE-5 inhibitors}

PACES: This trial looked at the effects of Sildenafil and epoprostenol in 267 patients with PAH [34]. The patients were all treated with epoprostenol for three months and when there was no dose adjustment necessary for four weeks, they were randomised to the addition of placebo or sildenafil as tolerated. The $6 \mathrm{MWD}$ was evaluated after 16 weeks of treatment and it increased by $28 \mathrm{~min}$ in the sidenafil cohort. There have been other studies in which simultaneously starting both the agents led to reduction in the mPAP.

\section{Endothelin receptor antagonist and PDE-5 inhibitors}

PHIRST: Both these agents are given orally and act on different receptors. The PHIRST study was designed to look at safety and efficacy of various doses of Tadalafil and patients were randomised to either placebo or background bosentan therapy [35]. This showed that there was an improvement in 6MWD of $32 \mathrm{~m}$ and that there was improvement in pulmonary hemodynamics. Also, there was increase in the time to clinical worsening at the higher doses of Tadalafil.

\section{Surgical Interventions}

\section{Balloon atrial septostomy}

Balloon atrial septostomy is a technique in which the interatrial septum is punctured followed by repetitive balloon dilatation to create an atrial defect. This leads to decompression of the right heart and increases left ventricle pre-load and cardiac output [36]. The result is a net increase in oxygen tissue delivery despite shunt induced hypoxemia, decreased right ventricular filling pressures and improvements in exercise capacity [37].

\section{Transplantation}

Transplantation is reserved for patients who have severe disease and fail to respond to maximal therapy. All functional class IV patients should be referred early as there is high mortality at later stages [38] The patients should be also started on medical therapy and if they respond, they can then be taken off the list. Those patients who remain in class III despite being on combination therapy should be listed as soon as possible. Either heart lung or bilateral lung transplantation can be done, depending on the center policy and donor availability.

\section{Special Considerations}

\section{Treatment of $\mathrm{PH}$ associated with left heart disease}

Left heart disease is one of the most common causes of $\mathrm{PH}$ and can be decreased by lowering left sided filling pressures. The drugs that can accomplish this include diuretics, nitrates, hydralazine, ACE inhibitors, beta blockers and nesiritide. In addition various interventions can be done including LV assist device, valvular surgery, resynchronisation therapy and heart transplantation to accomplish this goal. A small study showed that sildenafil has a beneficial effect on exercise capacity in patients with left heart disease. Currently the use of $\mathrm{PH}$ specific therapy is not recommended for patients with $\mathrm{PH}$ due to left heart disease and patients with out of proportion $\mathrm{PH}$ associated with left heart disease should be encouraged to join a clinical trial evaluating such therapy.

\section{Treatment of $\mathrm{PH}$ in Chronic lung disease}

The mainstay of treatment is that of the underlying lung disease. Long term oxygen therapy can be used in patients with chronic hypoxemia. The use of $\mathrm{PH}$ specific therapy is not recommended in patients with $\mathrm{PH}$ due to lung disease but patients who have out of proportion $\mathrm{PH}$ due to their lung disease should be referred to $\mathrm{PH}$ centers and enrolled in clinical trials which target $\mathrm{PH}$ specific therapy.

\section{Treatment of $\mathrm{PH}$ associated with chronic thromboembolic disease}

This is one of the most common causes of $\mathrm{PH}$. All patients with CTEPH should receive lifelong anti-coagulation to prevent recurrence. PEA is the treatment of choice as it can be potentially curative. The patients are selected based on the extent and location of thrombus. In general, proximal organised thrombi are an ideal indication while more distal thrombi are hard to completely remove. Clinical trials have showed that Bosentan results in a significant drop in PVR without any change in $6 \mathrm{MWD}$ and can be considered in inoperable patients. Bilateral lung transplantation is another option that be used in advanced cases not amenable to PEA.

\section{References}

1. McLaughlin VV, McGoon MD (2006) Pulmonary arterial hypertension Circulation 114: 1417-1431

2. Kovacs G, Berghold A, Scheidl S, Olschewski H (2009) Pulmonary arterial pressure during rest and exercise in healthy subjects: a systematic review. Eur Respir J 34: 888-894.

3. Naeije R, Mélot C, Niset G, Delcroix M, Wagner PD (1993) Mechanisms of improved arterial oxygenation after peripheral chemoreceptor stimulation during hypoxic exercise. J Appl Physiol 74: 1666-1671. 
4. Simonneau G, Robbins IM, Beghetti M, Channick RN, Delcroix M, et al. (2009) Updated clinical classification of pulmonary hypertension. J Am Coll Cardiol 54: S43-S54

5. Hatano S, Strasser T (1975) World Health Organization 1975. Primary pulmonary hypertension, Geneva: WHO

6. Humbert M, Morrell NW, Archer SL, Stenmark KR, MacLean MR, et al. (2004) Cellular and molecular pathobiology of pulmonary arterial hypertension. J Am Coll Cardiol 43: 13S-24S

7. Mereles D, Ehlken N, Kreuscher S, Ghofrani S, Hoeper MM, et al. (2006) Exercise and respiratory training improve exercise capacity and quality of life in patients with severe chronic pulmonary hypertension. Circulation 114: 1482 1489.

8. Bédard E, Dimopoulos K, Gatzoulis MA (2009) Has there been any progress made on pregnancy outcomes among women with pulmonary arterial hypertension? Eur Heart J 30: 256-265.

9. Bendayan D, Hod M, Oron G, Sagie A, Eidelman L, et al. (2005) Pregnancy outcome in patients with pulmonary arterial hypertension receiving prostacyclin therapy. Obstet Gynecol 106: 1206-1210.

10. Bonnin M, Mercier FJ, Sitbon O, Roger-Christoph S, Jaïs X, et al. (2005) Severe pulmonary hypertension during pregnancy: mode of delivery and anesthetic management of 15 consecutive cases. Anesthesiology 102: 1133-1137.

11. Rich S, Dantzker DR, Ayres SM, Bergofsky EH, Brundage BH, et al. (1987) Primary pulmonary hypertension. A national prospective study. Ann Intern Med 107: 216-223.

12. Fuster V, Steele PM, Edwards WD, Gersh BJ, McGoon MD, et al. (1984) Primary pulmonary hypertension: natural history and the importance of thrombosis. Circulation 70: 580-587.

13. Rich S, Seidlitz M, Dodin E, Osimani D, Judd D, et al. (1998) The short-term effects of digoxin in patients with right ventricular dysfunction from pulmonary hypertension. Chest 114: 787-792.

14. McLaughlin VV, Archer SL, Badesch DB, Barst RJ, Farber HW, et al. (2009) ACCF/AHA 2009 expert consensus document on pulmonary hypertension: report of the American College of Cardiology Foundation Task Force on Expert Consensus Documents and the American Heart Association: developed in collaboration with the American College of Chest Physicians, American Thoracic Society, Inc., and the Pulmonary Hypertension Association. Circulation 119 2250-2294.

15. Rich S, Kaufmann E, Levy PS (1992) The effect of high doses of calciumchannel blockers on survival in primary pulmonary hypertension. $\mathrm{N}$ Engl $\mathrm{J}$ Med 327: 76-81.

16. Sitbon O, Humbert M, Jaïs X, loos V, Hamid AM, et al. (2005) Long-term response to calcium channel blockers in idiopathic pulmonary arterial hypertension. Circulation 111: 3105-3111.

17. McLaughlin VV, Shillington A, Rich S (2002) Survival in primary pulmonary hypertension: the impact of epoprostenol therapy. Circulation 106: 1477-1482.

18. Barst RJ, Rubin LJ, Long WA, McGoon MD, Rich S, et al. (1996) A comparison of continuous intravenous epoprostenol (prostacyclin) with conventional therapy for primary pulmonary hypertension. The Primary Pulmonary Hypertension Study Group. N Engl J Med 334: 296-302.

19. Nunes H, Humbert M, Sitbon O, Morse JH, Deng Z, et al. (2003) Prognostic factors for survival in human immunodeficiency virus-associated pulmonary arterial hypertension. Am J Respir Crit Care Med 167: 1433-1439.

20. Badesch DB, Tapson VF, McGoon MD, Brundage BH, Rubin LJ, et al. (2000) Continuous intravenous epoprostenol for pulmonary hypertension due to the scleroderma spectrum of disease. A randomized, controlled trial. Ann Intern Med 132: 425-434.

21. Krowka MJ (2006) Evolving dilemmas and management of portopulmonary hypertension. Semin Liver Dis 26: 265-272.

22. Doran AK, Ivy DD, Barst RJ, Hill N, Murali S, et al. (2008) Guidelines for the prevention of central venous catheter-related blood stream infections with prostanoid therapy for pulmonary arterial hypertension. Int J Clin Pract Suppl : 5-9.

This article was originally published in a special issue, Pulmonary Hypertension handled by Editor(s). Dr. Zeenat Safdar, Baylor College of Medicine, United States
23. McLaughlin VV, Benza RL, Rubin LJ, Channick RN, Voswinckel R, et al. (2010) Addition of inhaled treprostinil to oral therapy for pulmonary arteria hypertension: a randomized controlled clinical trial. J Am Coll Cardiol 55: 19151922.

24. Simonneau G, Barst RJ, Galie N, Naeije R, Rich S, et al. (2002) Continuous subcutaneous infusion of treprostinil, a prostacyclin analogue, in patients with pulmonary arterial hypertension: a double-blind, randomized, placebocontrolled trial. Am J Respir Crit Care Med 165: 800-804.

25. Olschewski H, Simonneau G, Galiè N, Higenbottam T, Naeije R, et al. (2002) Inhaled iloprost for severe pulmonary hypertension. N Engl J Med 347: 322329

26. McLaughlin VV, Oudiz RJ, Frost A, Tapson VF, Murali S, et al. (2006) Randomized study of adding inhaled iloprost to existing bosentan in pulmonary arterial hypertension. Am J Respir Crit Care Med 174: 1257-1263.

27. Channick RN, Simonneau G, Sitbon O, Robbins IM, Frost A, et al. (2001) Effects of the dual endothelin-receptor antagonist bosentan in patients with pulmonary hypertension: a randomised placebo-controlled study. Lancet 358: 1119-1123.

28. Rubin LJ, Badesch DB, Barst RJ, Galie N, Black CM, et al. (2002) Bosentan therapy for pulmonary arterial hypertension. N Engl J Med 346: 896-903.

29. Galiè N, Olschewski H, Oudiz RJ, Torres F, Frost A, et al. (2008)Ambrisentan for the treatment of pulmonary arterial hypertension: results of the ambrisentan in pulmonary arterial hypertension, randomized, double-blind, placebo-controlled, multicenter, efficacy (ARIES) study 1 and 2. Circulation 117: 3010-3019.

30. Galiè N, Ghofrani HA, Torbicki A, Barst RJ, Rubin LJ, et al. (2005) Sildenafil citrate therapy for pulmonary arterial hypertension. N Engl J Med 353: 21482157

31. Galiè N, Brundage BH, Ghofrani HA, Oudiz RJ, Simonneau G, et al. (2009) Tadalafil therapy for pulmonary arterial hypertension. Circulation 119: 28942903.

32. Humbert M, Barst RJ, Robbins IM, Channick RN, Galiè N, et al. (2004) Combination of bosentan with epoprostenol in pulmonary arterial hypertension: BREATHE-2. Eur Respir J 24: 353-359.

33. O'Callaghan DS, Savale L, Jaïs X, Natali D, Montani D, et al. (2010) Evidence for the use of combination targeted therapeutic approaches for the management of pulmonary arterial hypertension. Respir Med 104 Suppl 1: 74-80.

34. Simonneau G, Rubin LJ, Galiè N, Barst RJ, Fleming TR, et al. (2008) Addition of sildenafil to long-term intravenous epoprostenol therapy in patients with pulmonary arterial hypertension: a randomized trial. Ann Intern Med 149: 521 530.

35. O'Callaghan DS, Gaine SP (2007) Combination therapy and new types of agents for pulmonary arterial hypertension. Clin Chest Med 28: 169-185.

36. Kurzyna M, Dabrowski M, Bielecki D, Fijalkowska A, Pruszczyk P, et al. (2007) Atrial septostomy in treatment of end-stage right heart failure in patients with pulmonary hypertension. Chest 131: 977-983.

37. Hopkins WE (2005) The remarkable right ventricle of patients with Eisenmenger syndrome. Coron Artery Dis 16: 19-25.

38. Keogh AM, Mayer E, Benza RL, Corris P, Dartevelle PG, et al. (2009) Interventional and surgical modalities of treatment in pulmonary hypertension. J Am Coll Cardiol 54: 67-77. 